\title{
The Institutional Environment of Health Reproduction as a Part of Human Capital Formation
}

\author{
Tatiana L. Lepikhina ${ }^{1} \&$ Yuliya V. Karpovich ${ }^{1}$ \\ ${ }^{1}$ Perm National Research Polytechnic University, Komsomolski ave, 29, Perm, Russian Federation \\ Correspondence: Tatiana L. Lepikhina, Perm National Research Polytechnic University, Komsomolski ave, 29, \\ Perm, Russia Federation. E-mail: 1-pstu@inbox.ru
}

Received: July 8, 2014 Accepted: July 24, 2014 Online Published: November 27, 2014

doi:10.5539/ass.v10n24p12 URL: http://dx.doi.org/10.5539/ass.v10n24p12

\begin{abstract}
Under conditions of the growing importance of human capital in the processes of Russia's sustainable development, the role of formal and informal institutions that provide the expanded reproduction of human capital at different levels becomes more and more significant. The subjects of the institutional environment of health reproduction processes as a part of human capital formation are presented in the issue, including identification of the key functions; a need to improve the management mechanisms of their interaction with the aim of improving the socio-economic performance of the human capital is indicated.
\end{abstract}

Keywords: human capital, health as an element of human capital, institutional environment of the human capital reproduction process, the functions of the institutional environment subjects, health management, performance indicators of the institutional environment of human capital reproduction process

\section{Introduction}

In the 1960s and 70s, the pioneering work of Schultz (1961) and Becker (1964) on human capital caused development economists to augment their standard economic growth models to allow for human capital investment to play a role (Hall, 2000). It is generally accepted that human capital is a reflection of the quality of labor capital, and human capital consists of economic value of knowledge, technology, ability, and healthy quality which condenses on laborers (Yang et al., 2006). Human capital usually has greater appreciation of space than material capital and other production factors, especially in the post industry era and in the stage of rapid economic knowledge development (Ma et al., 2014). The modern stage of economic transformations is characterized by the fact that human capital becomes the main value of the company, the defining factor for sustainable development and economic growth as the competitive advantages of modern firms, which are currently achieved mainly not through material resources, but at the expense of knowledge, information and innovation, which is owned by people. Generally, the formation of human capital mainly depends on the input of education, health and income, and so forth (Mankiw et al., 1992; Barro \& Lee, 1996). The differences among education investment, health investment, and family economic income invariably tend to rise up the differences of human capital stock directly (Somanathan, 1998; Ayalew, 2005), while the differences of human capital will lead to the differences of their effects.

Actualization of issues of human capital reproduction and management as part of the transition of Russian economy to a new level of development, which is characterized by the extent of the demand and use of new knowledge, requires the mobilization of new long-term sources of growth, which are based on qualitative improvement of human capital as a result of interaction between the state, firms and individuals. The reproduction of human capital as an economic category, expresses the combination of the processes of formation, preservation, development and improvement of human capital, including knowledge, skills, abilities of a person to work, and also his physical condition, intellectual and creative abilities. Extended reproduction of human capital in the framework of the above mentioned processes depends significantly on the effectiveness of socio-economic relations.

\section{Materials and Methods}

The reproduction of human capital implies the dynamic development of its components; it requires certain financial investments from the individual and firms, as well as from the state (Dobrynin, 1999). The much 
attention is given nowadays in domestic and foreign science to the processes of human capital reproduction. Human capital is distinct from physical capital, it cannot be separated from the personality, and, consequently, its reproduction is greatly influenced not only from economic but also from social processes and, above all, from the system of economic relations, within which the process of reproduction is carried out (Kristinevich, 2010).

In the frames of the regional and national economy reproduction process is considered as a mechanism of resources transformation into tangible and intangible benefits to ensure the activity of a certain territorially integrated society and economy (Oleinikova \& Critskiy, n. d.). Russian scientists (Ermakov, Dyatlov, Krakowskaya, et al., n. d.) study the process of human capital reproduction at the enterprise-level, defining it as a multistage process involving both the stage of functional circuit and stages of the natural, economic and innovative turnover, associated it respectively with the retirement and replacement of personnel at retirement, retraining of workers in connection with the modernization of the technique used.

However existing modern models of human capital reproduction at the individual, corporate and national levels do not take into account the impact of institutional environment on the efficiency of the process. As it has been rightly observed by I. Krakowskaya, human capital is created and reproduced not only as a result of the formal but also of informal ties and relations, largely determined with social and cultural traditions and the specific mentality of the participants of the reproduction process (Krakowskaya, 2009). A significant part of human capital formed outside the working and educational activities, in the process of direct communication. More generally, societal payoffs to improvements in the levels of both physical and human capital are likely dependent on the on the institutional context in which those investments occur. In countries with good institutions-where the social, political, and legal rules provide for secure property rights, unbiased contract enforcement, and reliance on market prices and profits and losses to guide economic activity-investments in capital are both privately beneficial to individuals and also create a positive return for society as a whole. In countries with poor institutions, however, the higher returns to investments in rent-seeking activities that plunder the wealth of others, through lobbying and lawsuit abuse, for example-draw significant resources into these privately beneficial, but socially unproductive activities. Investments in education produce more lobbyists, politicians, and lawyers, rather than engineers and scientists (Murphy et al., 1991).

In this regard, the study of the institutional environment and its influence on the processes of formation and development of human resources that provide the desired result from investments in staff based on the unique characteristic of this specific system of management processes and procedures should become the object of special importance.

Firstly define the concept of "institutional environment". Williamson defines the institutional environment as the rules that determine the context in which economic activity is carried out (Williamson, 1985). D. North draws attention to the fact that the institutional environment is the set of institutions at "constitutional level" that define permissible limits of the new institutions or codes in society (Bazueva, 2011). Moreover D. North clarifies that this institutional environment determines the degree and effectiveness of changes in the economic system. A. Shastitko in its definition puts the emphasis on the use of resources: "the institutional environment is one of the most important components of the institutional matrix, which surrounds the process of allocation of limited resources, and the identification of new opportunities for the use of existing resources and creating new ones" (Shastitko, 1999). Thus, it should be stated that the institutional environment creates conditions for a particular type of activity within the rules and limits defined in a system (Shelomentsev, 2009).

In the framework of this work we will refer back to the definition given by I. Williamson, as far as reproduction aspect is presented in his definition, in his opinion it is the elements of the institutional environment form the basis for production, exchange and distribution of objects in management.

It is known that the institutional environment in its content is not homogeneous. Therefore, the degree of conformity of its elements to each other can determine the degree of coherence, or, conversely, inconsistency of its content.

Through its numerous functions, subjects of the institutional environment play a significant role in the process of human capital reproduction. The efficiency of human capital reproduction processes is determined mainly with two basic functions-health and skills, consequently in the theory of management a special role is played by two components of human capital management: "knowledge management" and "health management". The object of study in this paper is the subjects of the institutional environment governing the process of health reproduction as a part of human capital. 


\section{Results}

Problems of health management as a component of human capital can be considered at the macro-, micro-, meso- and nanoeconomic levels. In accordance with the Federal law of the Russian Federation Nr 323-FZ "On fundamentals of protection of the health of citizens in the Russian Federation" health is defined as "a state of physical, mental and social well-being in which there are no diseases, and disorders of the functions of organs and systems of the body" (Federal law "On fundamentals of protection of the health of citizens in the Russian Federation", 2011). Health of the individual and society as a whole is formed under the influence of the complex of socio-economic, environmental, natural and climatic conditions of the country, region, etc. Here we can use different indicators of its condition and distinguish the health potential from the real state of the individual and the nation. The state of health (the implementation of the health management system) can be managed only taking into account the institutional environment forming health, the subjects of which can be arranged in a hierarchical order presented in the following diagram.
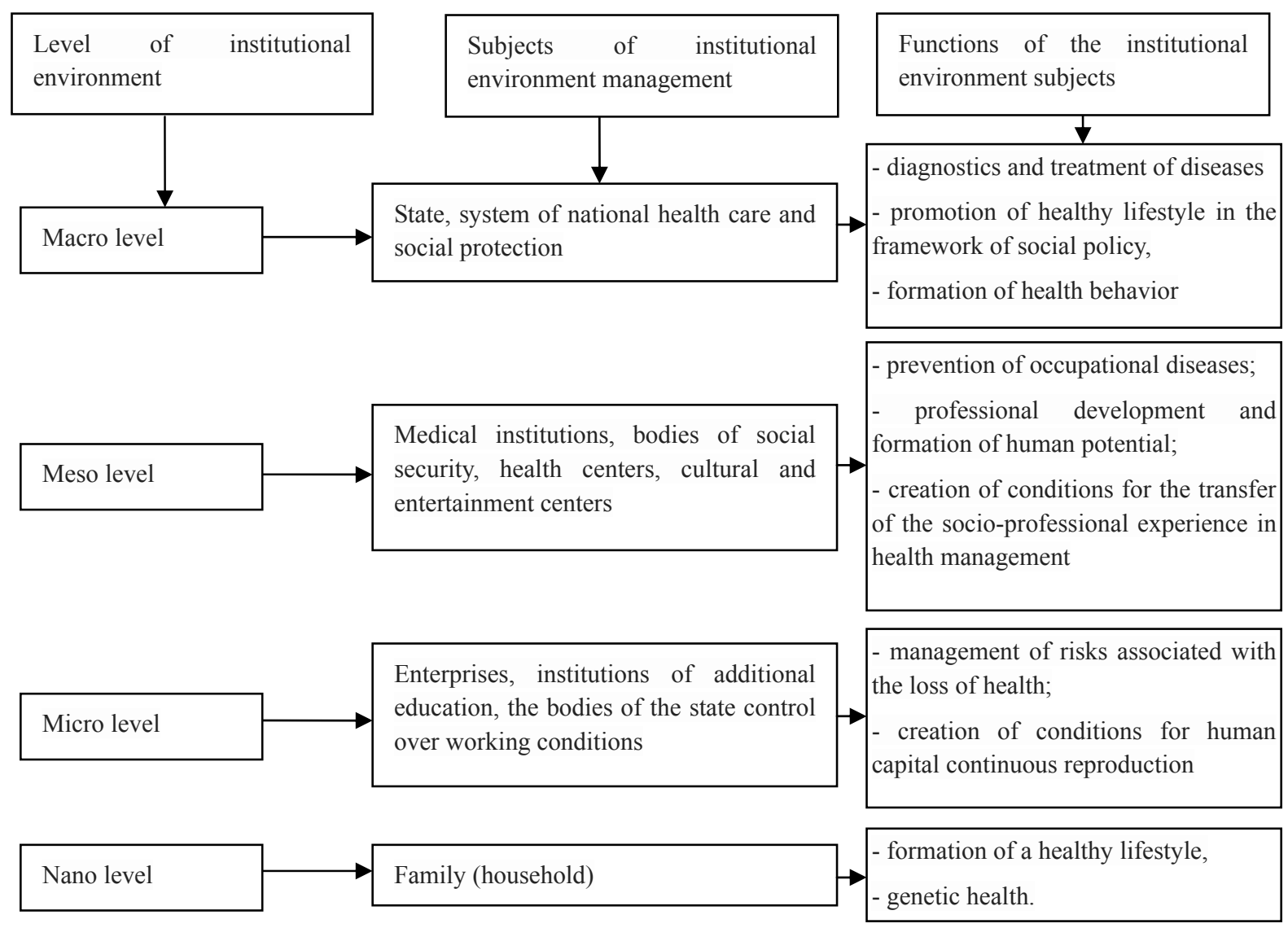

Figure 1. The subjects of management of institutional environment of reproductive health as part of human capital and their functions

Thus, four levels can be pointed out in the system of health protection institutions. In the figure shown above the family presents the original institution, which determines its value. The family determines the parameters of the genetic health and its conservation stipulated with the way of life; forms the key features of the individual that represents the core of qualitative characteristics of human capital.

The enterprises, being the basic institutions at micro-level, are the main consumers of the resource health, and therefore to some extent a kind of customers of the human capital quality, which is largely determined by the person's state of health. On the other hand, companies can affect the health of its employees through the system of labour safety, providing employees with access to the institutions of physical culture and recreation, culture, representing, in turn, the meso-level at hierarchical structure of health capital management. The health status of the employees at the enterprise is also a factor affecting the accumulation of human capital, and investing in the health of workers is an important part of the investment in the human capital of the enterprise (Loehr \& Schwartz, 2012). 
The task of coordination of actions for health promotion is fulfilled by the government (macro-level), which through the system and institutional structure at macro-and meso-levels provides formation of qualitative characteristics of the health resources (Kiseleva, 2012).

\section{Discussion}

Table 1. Performance indicators of the subjects of the health management institutional environment by the example of perm region

\begin{tabular}{|c|c|c|c|c|c|c|c|}
\hline $\begin{array}{l}\text { № } \\
\text { ח/п }\end{array}$ & Indicator & Level & 2000 & 2005 & 2010 & 2011 & 2012 \\
\hline 1. & Fertility & $\begin{array}{l}\text { Macro-, } \quad \mathrm{n} \\
\text { micro- } \\
\text { nano-levels }\end{array}$ & $\begin{array}{l}\text { meso-, } \\
\quad \text { and } 27701\end{array}$ & 29974 & 37304 & 37015 & 38931 \\
\hline 2. & Mortality & $\begin{array}{l}\text { Macro-, } \quad \mathrm{n} \\
\text { micro- } \\
\text { nano-levels }\end{array}$ & $\begin{array}{l}\text { meso-, } \\
\quad \text { and } 46338\end{array}$ & 49401 & 40371 & 38685 & 37453 \\
\hline 3. & $\begin{array}{l}\text { The number of doctors, thous. } \\
\text { people }\end{array}$ & $\begin{array}{l}\text { Macro- } \\
\text { meso-levels }\end{array}$ & and 15,7 & 14,98 & 14,3 & 14,4 & 13,2 \\
\hline 3.1 . & $\begin{array}{l}\text { The number of doctors per } 10 \\
000 \text { population }\end{array}$ & $\begin{array}{l}\text { 10Macro- } \\
\text { meso-levels }\end{array}$ & and 55,0 & 55,1 & 54,2 & 54,6 & 50,0 \\
\hline 4. & $\begin{array}{l}\text { The number of paramedical } \\
\text { personnel, thous. people }\end{array}$ & $\begin{array}{l}\text { alMacro- } \\
\text { meso-levels }\end{array}$ & and 33,2 & 30,3 & 28,9 & 28,2 & 28,0 \\
\hline 4.1 & $\begin{array}{l}\text { The number of paramedical } \\
\text { personnel per } 10 \\
\text { population }\end{array}$ & $\begin{array}{l}\mathrm{al}_{0}^{\mathrm{Meso}} \text { Mevels } \\
{ }_{\text {levels }}\end{array}$ & micro- 116,2 & 113,5 & 109,8 & 107,1 & 106,2 \\
\hline 5. & $\begin{array}{l}\text { Mortality by main groups of } \\
\text { causes (per } 10,000 \text { population), } \\
\text { including }\end{array}$ & $\begin{array}{l}\text { Meso-, micro- } \\
\text { nano-levels }\end{array}$ & o- and 1615,3 & 1806,1 & 1528,6 & 1469,6 & 1422,6 \\
\hline 5.1 & $\begin{array}{l}\text { some infectious and parasitic } \\
\text { diseases }\end{array}$ & & 23,6 & 32,4 & 27,9 & 28,9 & 29,6 \\
\hline 5.2 & Neoplasms & & 196,7 & 193,7 & 197,6 & 199,5 & 201,5 \\
\hline 5.3 & $\begin{array}{l}\text { diseases of the circulatory } \\
\text { system }\end{array}$ & & 826,2 & 954,5 & 856,7 & 830,8 & 794,6 \\
\hline 5.4 & respiratory diseases & & 81,5 & 89,4 & 58,9 & 61,6 & 51,7 \\
\hline 5.6 & diseases of digestive organs & & 50,2 & 90,7 & 79,1 & 80,6 & 80,0 \\
\hline 5.7 & external causes of death & & 310,4 & 314,4 & 227,1 & 193,2 & 183,5 \\
\hline 6. & $\begin{array}{l}\text { Employed in conditions that do } \\
\text { not meet hygienic standards of } \\
\text { working conditions }\end{array}$ & ${ }_{\text {of }}^{\text {lo }}{ }_{\text {Micro- }}$ & and 28,3 & 27,7 & 36,1 & 47,8 & 48,1 \\
\hline 7. & $\begin{array}{l}\text { Funds spent on the measures of } \\
\text { labour protection per year, } \\
\text { thous. rubles }\end{array}$ & $\begin{array}{l}\mathrm{f} \\
\mathrm{r} \text { Micro- } \\
\text { meso-levels }\end{array}$ & and $_{H / д}$ & 3410625,1 & 5628497,6 & 4114520,0 & 4609468,2 \\
\hline 8. & $\begin{array}{l}\text { The number of people first } \\
\text { diagnosed with occupational } \\
\text { disease }\end{array}$ & ${ }_{\text {meso-levels }}^{\mathrm{st}}$ Micro- & and $_{H / д}$ & 137 & 148 & 157 & 104 \\
\hline 9. & $\begin{array}{l}\text { The number of people injured } \\
\text { in accidents on manufacture } \\
\text { with disabilities, people }\end{array}$ & $\begin{array}{l}\mathrm{d}_{\text {Micro- }} \\
\mathrm{e}_{\text {nano-levels }}\end{array}$ & and $_{H / д}$ & 2192 & 1328 & 1155 & 1043 \\
\hline
\end{tabular}

Source: data of the Territorial body of Federal statistics service of the Perm region, the State report "On sanitary and epidemiological situation in the Perm territory in 2013".

Health and culture authorities, representing state institutions for the preservation and strengthening of the health capital, considered by us as an element of human capital, contribute to the realization of the people's aspirations to improve the health capital quality. Transport, communication and information systems, emerging in the implementation of the relevant state target programs, ensure freedom of movement, and therefore access to health services, establishments of leisure and physical culture. However, despite the development of certain 
institutions of capital health reproduction the analysis of statistical data shows a low of their effectiveness in the field of support of the human capital reproduction processes. The analysis of some efficiency indicators of functioning institutions of health capital reproduction in Perm region (meso-level) are carried out in the paper. The results are presented in Table 1.

The table shows both positive and negative impact of management decisions at different levels of the institutional environment hierarchy. This dynamics shows that most of the figures are the cumulative result of decisions taken at different levels of the hierarchy. Thus, the first two indicators are included in a group of demographic indicators and prove the effectiveness of management actions (the birth rate has increased in Perm region from 2000 to 2012 by $40.5 \%$, the mortality rate decreased by $20.2 \%$ ). The third and fourth indicators indirectly characterizing the availability of medical services to the population of the region, have a negative trend, the number of doctors and nurses has decreased by $15.9 \%$ and $16.7 \%$, respectively, while mortality by main groups of causes only decreased by $12 \%$, and for some reasons it has even increased (from infectious and parasitic diseases, diseases of digestive organs and tumors). This result can be explained, on the one hand, with subjective reasons, such as the unwillingness of the population to visit doctors (nano-level), and late diagnosis as a consequence, on the other hand it is inaccessibility of some medical services related to diagnosis and effective treatment of the revealed diseases (meso- and micro-levels). Morbidity of socially significant diseases related to poor environmental situation only partially reflected in official statistics. So, cancer diseases remain without proper attention from the medical professionals. Low accessibility of specialized medical care, the lack of specialists in rural areas, and limited professional competence of medical workers, forcing the population to turn to alternative sources of health care.

In relation to the working population risk health groups include workers employed in conditions that do not meet hygienic standards of working conditions, and for the last 12 years this index increased 1.7 times. This negative trend is a result of inefficient managerial decisions both at the micro-, meso- and macro levels. At the micro level, the employer does not tend to guarantee employees a safe working environment, and at the meso- and macro-levels legal framework is weakly developed and system of control over a condition of workplaces is ineffective. However, the growth of expenses on labour protection on $35.15 \%$ has led to a reduction in the number of people first diagnosed with occupational disease by $24 \%$, the number of people injured in accidents on manufacture has reduce on $52.42 \%$.

\section{Conclusion}

The study carried allows identifying priority areas requiring development and acceptance of effective administrative decisions:

a) in the field of demographic policy, more attention should be paid to the problem of regulating the mortality;

b) in the field of policy organization of health care including the health care system reform (reduction of inpatient care, medical staff), it is necessary to consider the dynamics of morbidity and mortality for individual groups of causes;

c) management of occupational health requires the strengthening of interaction between levels managerial decision-making.

The results of the analysis allow concluding that a complete reproduction of human capital is possible only with the implementation of socially and economically sound investments from family, business and the state, aimed at the formation and reproduction of human capital and ensuring the foundations of health-preservation behavior. The present demographic situation, due to low level of public health in the Russian Federation can lead to falling of efficiency of human capital reproduction processes at all levels that will impede further economic development of the country. Thus the question about the necessity of formation of effective system of human capital reproduction, changes in behavior of all participants of the process, the formation of the health care culture, education activity in health becomes more urgent (Lepikhina \& Karpovich, 2012). It is necessary to inform workers about behavioral risk factors and promote the physical culture and the creation of infrastructure conditions for self-preservation and strengthening of individuals and their health.

\section{References}

Ayalew, T. (2005). Parental preference, heterogeneity, and human capital inequality. Economic Development and Cultural Change, 53, 381-407. http://dx.doi.org/10.1086/425377

Barro, R., \& Lee, J. (1996). International measures of schooling years and schooling quality. The American Economic Review, 86(2), 218-223. 
Bazueva, E. (2011). Institutional environment of modern Russia: Gender criterion of effectiveness. Bulletin of the University of Perm. Series: Economics, 2, 48-60.

Dobrynin, A. (n. d.). Human capital in transitive economy: Formation, evaluation, efficiency of use (p. 359). $\mathrm{SPb}$.: Science, 1999.

Federal law of the Russian Federation dated November 21, 2011 Nr. 323-FZ "On fundamentals of protection of the health of citizens in the Russian Federation" (p. 80). Prospekt, Moscow.

Hall, C. (2000). Investment in education: Public and private returns (p. 352). Washington, DC: Joint Economic Committee.

Kiseleva, L. (2011). Political economy of the health resource (p. 223). NGU, Tyumen.

Krakowskaya, I. (2009). The investment processes in human capital management system of the organization competitiveness. Creative economy, 3(27), 32-43.

Kristinevich, S. (2010). Institutional Conditions of the Human Capital Reproduction in the Innovation Economy. Problems of Management, 3(27), 48-53.

Lepikhina, T., \& Karpovich, Y. (2012). Institute of health as an element of management of human capital. Problems of modern economy, 4, 117-119.

Loehr, D., \& Schwartz, T. (2003). The Power of Full Engagement: Managing Energy, Not Time, Is the Key to High Performance and Personal Renewal (p. 256). Work Life Balance in Business. Free Press, NY.

Ma, J., Ma, Y., Bai, Y., \& Xia, B. (2014). Study on the Technical Efficiency of Creative Human Capital in China by Three-Stage Data Envelopment Analysis Model. Discrete Dynamics in Nature and Society. http://dx.doi.org/10.1155/2014/964275

Mankiw, N., Romer, D., \& Weil, D. (1992). A contribution to the empirics of economic growth. Quarterly Journal of Economics, 5. http://dx.doi.org/10.2307/2118477

Murphy, M., Shleifer, A., \& Vishny, R. (1991). The allocation of talent: Implications for growth. Quarterly Journal of Economics, 106, 503-530. http://dx.doi.org/10.2307/2937945

Shastitko, A. (1999). The institutional environment of management in Russia: Main characteristics (p. 519). Where is Russia going? The crisis of the institutional systems: Century, decade, year. Logos, Moscow.

Shelomentsev, A. (2009). Theory and methodology of the evolution of the business communities in the real sector of the national economy (p. 219). Ekaterinburg: Uro RAN.

Somanathan, R. (1998). School heterogeneity, human capital accumulation, and standards. Journal of Public Economics, 67, 369-397. http://dx.doi.org/10.1016/S0047-2727(97)00066-2

State report On sanitary and epidemiological situation in the Perm territory in 2013. Management Rospotrebnadzor Perm region, FBUZ "Center of hygiene and epidemiology in the Perm region", Perm. Retrieved July 20, 2014, from http://base.consultant.ru/regbase/cgi/online.cgi?req=doc;base=RLAW $368 ; \mathrm{n}=50638$

Williamson, O. (1985). The Economic Institutions of Capitalism: Firms, Markets, Relational Contracting (p. 405). Free Press, NY.

Yang, J., Gong, L., \& Zhang, Q. (2006). Human capital formation lands its effects on economic growth. Management World, 5, 10-18.

\section{Copyrights}

Copyright for this article is retained by the author(s), with first publication rights granted to the journal.

This is an open-access article distributed under the terms and conditions of the Creative Commons Attribution license (http://creativecommons.org/licenses/by/3.0/). 